\title{
O USO DA CONTABILIDADE COMO OBJETO DE TRANSPARÊNCIA NAS ENTIDADES RELIGIOSAS: UM ESTUDO DE CASO EM IGREJAS BATISTAS DE FEIRA DE SANTANA
}

\section{THE USE OF ACCOUNTING AS AN OBJECT OF TRANSPARENCY IN RELIGIOUS ENTITIES: A CASE STUDY IN BAPTIST CHURCHES OF FEIRA DE SANTANA}

\author{
Thayná Santos Silva; Mirian Gomes Conceição²; Alison Silva Ferreira ${ }^{3}$; Robson Lima Rodrigues ${ }^{4}$
}

\section{RESUMO}

O objetivo desta pesquisa foi verificar o uso da contabilidade como objeto de transparência pelas Igrejas Batistas de Feira de Santana. Para tanto, foi utilizado metodologia qualitativa e técnica de estudo de caso, com questionário aplicado a duas instituições religiosas pertencentes a Convenção Batista da Bahia e Convenção Batista Brasileira. Os resultados demonstram que o perfil dos respondentes é de homens experientes, com formação superior em administração e idade entre 43 e 59 anos. As igrejas possuem funcionários registrados e faz uso da contabilidade para fins fiscais, e, inclusive uma delas utiliza contabilidade com a finalidade gerencial. As organizações estudadas também se propõem a utilizar os relatórios que a contabilidade oferece, sobretudo o fluxo de caixa. Considera-se, para os respondentes, que a ciência contábil é uma ferramenta promotora de accountability, e, portanto, os resultados financeiros devem ser apresentados a toda igreja, nas reuniões, com uso dessa ciência como ponte para validar os dados e conferir credibilidade. Principalmente, por que, segundo entendem os quesitonados, responsáveis pelas igrejas, através da transparência é possível manter a captação de recursos, necessários a qualquer organização, na medida em que se propõe a apresentar a origem e destinação dos mesmos, objetivo que a contabilidade detém. Portanto, estudos como este, que vinculam a ciência contábil e suas demonstrações podem ser consideradas circustanciais no desenvolvimento do país, pois promovem discussões de caráter social e econômico, inclusive nas empresas sem finalidade lucrativa.

PALAVRAS-CHAVE: Contabilidade. Transparência. Terceiro Setor. Igrejas Batistas.

1 Graduada em Contabilidade. Faculdade Anísio Teixeira.

2 Mestre em Contabilidade pela Universidade Federal da Bahia (2013) e graduada em Ciências Contábeis pela Universidade Federal da Bahia (2010). Atuou como gerente financeiro em distribuidoras de produtos químicos nos estados de SP, MG e RS durante 4 anos. Foi coordenadora da Comissão Própria de Avaliação (CPA) da Faculdade Anísio Teixeira (FAT). Atualmente é professora do Curso de Ciências Contábeis da FAT e membro da Comissão de Assuntos Relacionados à Contabilidade Ambiental do Conselho Regional de Contabilidade da Bahia (CRCBA). Desenvolve pesquisa no Laboratório de Pesquisa em Contabilidade de Gestão da UFBA. Atua em temas ligados, principalmente, à Contabilidade social e ambiental, Educação e Pesquisa Contábil e Gestão de Resíduos Sólidos.

3 Graduado em Ciências Contábeis. Especialista em Gestão Ambiental. MBA em andamento em Gestão Contábil e Finanças Empresariais. Técnico em Química. Experiências em Controladoria, com atividades de controle de estoques e custos, processos administrativos, financeiros e contábeis. Palestrante e professor particular das disciplinas de Controladoria, Análise das Demonstrações Contábeis, Contabilidade de Custos, Orçamento, Auditoria e TCC. Pesquisador na área de Finanças, Terceiro Setor e Contabilidade Ambiental. Participa do Grupo: Contabilidade e Sociedade, Pesquisa e Extensão de Feira de Santana (CSPEFS).

4 Possui graduação em Ciências Contábeis pela Faculdade Anísio Teixeira e Especialização em Finanças e Gestão Contábil pela Faculdade Católica Paulista. Participa do Grupo: Contabilidade e Sociedade, Pesquisa e Extensão de Feira de Santana (CSPEFS) 
REVISTA

Terceiro Setor \& Gestão
O USO DA CONTABILIDADE COMO OBJETO DE TRANSPARÊNCIA NAS ENTIDADES

RELIGIOSAS: UM ESTUDO DE CASO EM IGREJAS BATISTAS DE FEIRA DE SANTANA

Thayná Santos Silva; Mirian Gomes Conceição; Alison Silva Ferreira; Robson Lima Rodrigues

\section{ABSTRACT}

The objective of this research was to verify the use of accounting as an object of transparency by the Baptist Churches of Feira de Santana. For that, a qualitative and technical methodology was used, with a questionnaire applied to two religious institutions belonging to the Baptist Convention of Bahia and the Brazilian Baptist Convention. The results show that the profile of the respondents is of experienced men, with bachelor degree in administration and age between 43 and 59 years. Churches have registered employees and make use of accounting for tax purposes, and even one of them uses accounting for management purposes. The organizations studied also propose to use that reports that offers the accounting, especially cash flow. For the respondents, it is considered that accounting science is a tool that promotes accountability, and therefore financial results should be presented to every church in meetings, using this science as a bridge to validate data and confer credibility. Mainly, because, according to the questioned ones, responsible for the churches, through the transparency it is possible to maintain the fundraising, necessary for any organization, in as much as it proposes to present the origin and destination of the same, objective that the accounting holds. Therefore, studies such as this, which link accounting science and its demonstrations, can be considered as circumstantial in the country's development, as they promote discussions of a social and economic nature, including non-profit companies.

KEYWORDS: Accounting. Transparency. Third Sector. Baptist Churches. 


\section{INTRODUÇÃO}

A contabilidade, para aqueles que não conhecem, remete uma ideal central de atividade ligada a números, talvez, pior tão complexa quanto a própria matemática, porém esse não é o fundamento da ciência contábil. Apesar de ter como base a matématica e a estatística, a contabilidade também abrange outros campos do conhecimento, como as relações humanas nas organizações, ética, sustentabilidade e noções de administração, tornando uma ciência social aplicada. E por ela ser essa ciência social, dinâmica e prática, se torna cada vez mais desafiador para os profissionais se adequarem a ela.

Devido a sua importância e utilidade nos mais diversos campos da atividade humana, a ciência contábil é utilizada por diferentes tipos de usuários, e em todas as áreas o uso da contabilidade se faz necessário para produção de relatórios e resultados. Contudo, faz-se necessário que a contabilidade seja objeto de transparência, principalmente para as empresas sem finalidade lucrativa, objeto deste trabalho.

As entidades que compõe o Terceiro Setor, portanto, não podem visar o lucro como resultado, e sim a produção intelectual, científica ou social. Neste contexto cita-se, como exemplo: as ONGs, as Cooperativas, Entidades Filantrópicas, Organizações Religiosas etc. Trata-se de instituições que cada vez mais vem obtendo crescimento, principalmente nos últimos anos, como tentativa de novas organizações socioeconômicas, representando uma excelente área de atuação para profissionais como os contadores.

As instituições que fazem parte do Terceiro Setor, como as Organizações Religiosas, desfrutam do direito da imunidade tributária, no entanto, isso não significa, no entanto, isenção das obrigações para prestações de contas. Elas devem ser transparentes e realizar suas atribuições para à sociedade civil, o Estado, os próprios colaboradores, mantenedores e membros, que voluntariamente prestam serviços para o sustento e desenvolvimento das suas atividades.

Com base no contexto apresentado, a presente pesquisa traz a seguinte problemática: Como se dá o uso da contabilidade como objetivo de transparência nas Igrejas Batistas de Feira de Santana?

Portanto, esta pesquisa pretende analisar e de- tectar se existe, dentro das Instituições Religiosas, especificamente: Igrejas Evangélicas Batistas, o uso da contabilidade com a finalidade de oferecimento de transparência, não apenas para o ponto de vista interno, ou seja, para os membros e fiéis, mas como esclarecimento de suas atividades tanto para a sociedade civil quanto para o Estado.

Considera-se assim que o objetivo principal deste trabalho consiste em verificar o uso da contabilidade como objeto de transparência pelas Igrejas Batistas de Feira de Santana. Contudo para alcançá-lo será necessário indentificar quais são os processos de transparência nessas entidades; verificar as ferramentas que são utilizadas para o obejetivo de traspareciar e evidenciar as contribuições que a contabilidade pode oferecer na gestão dos recursos para as Igrejas evangélicas.

As entidades integrantes do terceiro setor realizam diversas atividades para desenvolvimento cultural, científico e religioso da sociedade e são consideradas fundamentais para a população, pois através destas propostas sem fins lucrativos, alternativas a iniciativa privada e pública, se consegue reduzir problemas sociais. Portanto, pesquisas que visam estudar a transparência em entidades sem finalidade de lucros se faz importante, pois inferem credibilidade aos relatórios que são apresentados aos integrantes dessas organizações.

Além disso, as pesquisas em Contabilidade de Terceiro Setor vêm crescendo no decorrer dos anos, mas ainda são escassas e, portanto, é necessário incentivar a produção científica nesta área temática, sobretudo porque se sabe que a construção do saber através da pesquisa e extensão também auxilia na implantação de melhores profissionais no mercado de trabalho, principalmente motivando o interesse dos contadores em especializar-se e trabalhar com entidades sem fins lucrativos.

\section{REFERENCIAL TEÓRICO}

\subsection{Contabilidade e Terceiro Setor}

A contabilidade é uma ferramenta circunstancial para subsidiar as entidades e seus gestores na tomada de decisões, sejam no caráter financeiro, ge- 
rencial ou econômico. Para Sá (2008) a finalidade da contabilidade possui uma abrangência considerável, mas podemos citar, dentre outros: o papel de orientar a administração de riquezas e progresso das empresas, previsionamento de controles financeiros, auditoria, perícia; além da própria emissão de relatórios e de sua opinião (análise).

Basicamente o instrumento utilizado pela ciência contábil para tornar possível tais fundamentos, são as demonstrações contábeis e os relatórios gerenciais que essa área do conhecimento se prontifica a apresentar. Trata-se de dados importantes sobre o passado das entidades.

Segundo Souza (2015), essas demonstrações objetivam o fornecimento de informações úteis para diversos usuários: investidores, acionistas, financiadores, administradores, entre outros, portanto essas demonstrações financeiras surgiram da necessidade de uma avaliação periódica a respeito da saúde financeira e econômica das entidades.

A divisão da economia e, por consequência, dessas empresas é classificada, portanto, de acordo com seu setor. O primeiro setor é o próprio poder público. Segundo Tachizawa, Pozo e Alves (2012), esse grupo é representado pelos órgãos da administração direta e indireta, empresas públicas, sociedades de economia mista, autarquias, fundações e estatais.

O segundo setor, conforme Bento (2010), é o mercado, setor produtivo que possui finalidade lucrativa. Por fim, Araújo (2005) infere que as entidades do terceiro setor não possuem finalidade lucrativa, e são compostas por instituições privadas de interesse público.

Martins (2008) defende que o objetivo institucional das ESFL's é, portanto, provocar mudanças sociais, e através de doações, contribuições, subvenções e prestação de serviços comunitários essas entidades geram suas principais fontes de recursos financeiros e materiais. Segundo o autor, como lucro não é um fim dessas entidades, não há distribuição de proventos.

O surgimento do terceiro setor, segundo Santos e Silva (2008), iniciou diante da visualização da incapacidade do Estado em solucionar os problemas pós-sistema capitalista, a citar: desigualdades, poluições, violências e demais problemas relacionados a cultura, sociedade, economia e política.

Conforme citam Martins et al. (2011), esse setor é, portanto, uma junção dos outros dois setores, pois, os recursos financeiros, geralmente advém da iniciativa privada, mas o alvo desejado é o público, portanto, são entidades que podem conter objetivos filantrópicos, sociais, culturais, recreativos, religiosos, artísticos.

Segundo Freitas (2014), as Entidades Sem Fins Lucrativos, atualmente possuem uma parcela considerável no cenário nacional e prestam relevantes serviços na sociedade moderna. Essas entidades já possuíam, em 2005, um registro de 601.611 (IBGE, 2012).

Em um levantamento registrado no ano de 2010, a nova pesquisa realizada pelo órgão observou uma redução nestes números, totalizando 556,8 mil entidades cadastradas, no entanto, o salário médio dos trabalhadores das empresas consideradas Fundações Privadas e Associações sem Fins Lucrativos (FASFIL) aumentou $6,2 \%$.

Essas instituições, portanto, são ligadas à sociedade ainda que indiretamente, pois atuam na prestação de serviços, por este motivo, se faz circunstancial que estas entidades se tornem cada vez mais transparentes, tanto em relação as suas atividades quanto sua gestão (MARIO et al. 2013).

Portanto, na opinião de França (2007), devido ao crescimento dessas entidades e de sua representatividade social, é notável uma imposição por mais qualidade no processo de gestão dessas entidades, demandando sistemas de controle mais sofisticados.

Por isso, se faz necessário o uso da contabilidade, principalmente nestas instituições que dependem da transparência para sua sobrevivência, por se tratar de empresas sociais (BARROS, 2011).

Isso por que, segundo Martins et al. (2011), quanto mais nitidez na mensuração dos processos operacionais, maiores as chances de obtenção de recursos e continuidade da credibilidade. E como as características dessas empresas são próprias e especiais, é necessário o aprofundamento através das pesquisas (MEDEIROS, GALVÃO e OLIVEIRA, 2015).

Para tanto, a elaboração das demonstrações contábeis, devem seguir as orientações previstas na norma ITG/2002, do Conselho Federal de Contabili- 
dade (2012), que inferem que os relatórios contábeis devem ser elaborados pela entidade sem resultar em lucro, sendo obrigatória a apresentação do: Balanço Patrimonial, da Demonstração do Resultado do Período, Demonstração das Mutações do Patrimônio Líquido, da Demonstração dos Fluxos de Caixa e das Notas Explicativas, conforme orienta a NBC TG 26 e NBC TG 1000.

Olak e Nascimento (2010) completam que além da contabilidade, na figura das demonstrações contábeis, as ESFL's podem e devem utilizar os relatórios da administração e o próprio parecer dos auditores independentes que se constituem junto as DC's, excelentes ferramentas, não apenas para transparência, mas gestão e prestação de contas.

\subsection{Entidades religiosas: contexto das igrejas evangélicas}

A constituição prevê em seu artigo $5^{\circ} \mathrm{o}$ direito ao culto religioso, inclusive protegendo os locais de desenvolvimento dos mesmos e suas liturgias. Portanto, conforme infere Silva Jr. (2018), as igrejas são voltadas especialmente à religiosidade e à profissão de fé.

Para Drucker (2012), a transformação do homem, no estágio social, espiritual e coletivo, além da sua própria colocação dentro do âmbito social e a aprendizagem fomentam os objetivos das entidades religiosas no contexto social.

O Governo Federal também entende que a prática religiosa é importante na vida humana, por isso, determinou imunidade tributária aos templos religiosos de qualquer natureza. Para Paulsen (2017), este incentivo é uma forma de auxiliar as religiões na produção da profissão da fé, prática de virtudes e elevação espirituais, tríplice de atributos essenciais à condição de vida humana. Mas isso não desobriga as igrejas a apresentarem suas obrigações principais e acessórias (SILVA JR., 2018).

Entende-se, portanto, que as igrejas são importantes como entidades integrantes do Terceiro Setor (FREITAS, 2014). No entanto, a recomendação que se tem é que esses ambientes religiosos, inclusive, as igrejas protestantes, se organizem como pessoas jurídicas, especialmente como fundação ou associa- ção, considerando aspectos como: membros, patrimônio e práticas de controle (SZAZI, 2006).

Neste contexto, sabe-se que a religião cristã possui a maior quantidade de membros no Brasil, sendo ainda a maior religião do mundo, juntamente com o Islamismo, segundo os dados inferidos pelo site The World Factbook.

No Brasil, segundo o IBGE (2010), os evangélicos ou protestantes, representam $22 \%$ do total de integrantes nos grupos religiosos, contudo nos últimos 40 anos, houve um crescimento de mais de $230 \%$ nos adeptos a essa religião. Segundo o órgão, a expectativa é que até 2020 , a população brasileira seja em maior parte protestante.

O mesmo senso do IBGE (2010) expõe outra informação interessante, principalmente, considerando os objetivos e aplicabilidade da pesquisa atual: as Igrejas Batistas foram quantificadas pelo órgão como a segunda maior denominação dentro das diversas instituições protestantes, atrás apenas das Igrejas pertencentes à Assembleia de Deus.

Segundo Freitas (2014), diante de tal representatividade, as Igrejas Batistas (bem como as demais instituições religiosas) devem continuadamente respeitar e atender as normas e procedimentos tanto do fisco, quanto os relatórios contábeis. Pois é através do uso contínuo da contabilidade e de suas informações fidedignas e relevantes que se permite a tomada de decisões, bem como objeto de transparência, proporcionando credibilidade, principalmente na visão daqueles que financiam suas atividades: os contribuintes.

Isso porque, considerando a opinião de Faria e Rego (2014), parte considerável dos recursos adquiridos pelas igrejas é adquirida através das doações dos fiéis, pois as fontes de recursos são dos próprios integrantes, chamados de dizimistas e ofertantes, ou seja, os recursos são oriundos de contribuições sistemáticas de seus associados em forma de dízimos e ofertas (FREITAS, 2014). O que confere a necessidade de utilizar o Disclosure.

\subsection{Transparência e Prestação de Contas}

Para Albuquerque (2006), igualmente a uma empresa ou um órgão governamental, as organiza- 
ções do Terceiro Setor, incluindo as igrejas, necessitam de uma gestão eficiente e eficaz, principalmente se tratando recursos humanos, potencial financeiro e disponibilidade de material com a finalidade de desenvolver seus planos e propósitos.

Especialmente por que, segundo Stephano e Buesa (2013) o fato das igrejas serem constantemente questionadas, sobretudo as evangélicas, a respeito da aplicação e gestão dos seus recursos, aumentam ainda mais suas responsabilidades.

Assim, a contabilidade, se torna, neste contexto, o instrumento impreterível que além de servir de subsídio a tomada de decisões, materializa-se como a prova da destinação dos recursos, ou seja, é uma ferramenta que também serve como prova do bom trabalho da gestão, realizada nas igrejas protestantes pelos pastores, missionários, e obreiros, em geral.

Rodrigues (2014) cita que um dos requisitos para uma boa transparência se refere à comunicação de informações aos seus doadores sobre a aplicação dos recursos, a prestação de contas. Assim, as igrejas possuem o intuito de demonstrar perante toda a sociedade que os objetivos estão sendo cumpridos (accountability), é circunstancial o uso da transparência e, evidenciando o seu patrimônio através da prestação de contas (FARIA; REGO, 2014).

Essa accountability é entendida por Carneiro, Oliveira e Torres (2011) como a ferramenta para o exercício da transparência. Segundo os autores, esse termo, oriundo do inglês não possui uma tradução específica no nosso idioma, mas basicamente pode ser entendido como a responsabilidade na prestação de contas.

Sendo assim, nas organizações sem fins lucrativos, inclusive nas instituições religiosas e por fim, nas igrejas evangélicas, essa accountability seria o cumprimento da missão gerencial de demonstrar como foi realizada a destinação de recursos das doações.

Portanto, considerando o pensamento de Stephano e Buesa (2013), ao se retratar a respeito da transparência, não significa a invasão da privacidade da administração eclesiástica, mas que os registros contábeis sejam feitos da melhor maneira, afinal.

Além disso, para realização deste Disclosure (evidenciação), é necessário, segundo Ludicibus (2007), apresentar a situação patrimonial através do balanço, indispensável demonstrar o Superávit ou Déficit como resultado do exercício, e as origens e aplicações de recursos.

Acrescenta-se ainda que essa transparência, na verdade, além de um atributo importante no exercício da evidenciação, é, conforme Faria e Rego (2014) um artefato para inspirar a confiabilidade dos fiéis, esse princípio faz com que a entidade continue captando recursos para continuidade de suas atividades.

\section{PROCEDIMENTOS METODOLÓGICOS}

A pesquisa possui um caráter qualitativo, pois, conforme cita Gerhardt e Silveira (2009) a pesquisa qualitativa preocupa-se com o ponto de vista real que não podem ser quantificados, centrando-se na clareza e explicação.

Enquanto, se tratando de objetivos, a pesquisa pode ser entendida como exploratória, considerando Cervo e Bervian (2007) que inferem que nesse tipo de pesquisa não há hipóteses elaboradas, mas uma busca de informações sobre determinado assunto de estudo.

Também deve ser vista como um estudo de caso, pois conforme definem Duarte e Barros (2006) este tipo de estudo de deve ser visto como uma análise intensiva, empreendida numa única ou em algumas organizações reais.

Em relação aos procedimentos técnicos, o presente trabalho se utiliza da metodologia proposta por França (2007) utilizando-se de revisão bibliométrica com o objetivo de construir o conhecimento e discussões acerca do tema; e pesquisa de campo para investigar o uso da contabilidade como ferramenta promotora de transparência nas Igrejas.

O procedimento de pesquisa de campo, conforme Fonseca (2002) caracteriza-se pelas investigações em que, além da pesquisa bibliográfica e/ou documental, se realiza coleta de dados junto a pessoas, com o recurso de diferentes tipos de pesquisa.

Para realização dos procedimentos foi utilizado um questionário fechado. Segundo Gil (2010) esse tipo de instrumento pode ser visto como uma técnica de investigação composta por um conjunto de questões que são submetidas a pessoas com o propósito de obter informações. Assim, para realização dessa 
pesquisa foi utilizada como amostras, as Igrejas $\mathrm{Ba}$ tistas de Feira de Santana integrantes da Convenção Batista do Estado da Bahia e também da Convenção Batista Nacional. Essas organizações foram escolhidas por critério de conveniência.

Os questionários foram aplicados aos líderes (pastores, seminaristas, presidentes do conselho fiscal ou administrativo etc.) de cada uma das igrejas descritas na Tabela 1.

Tabela 1. Amostra da pesquisa

\begin{tabular}{|c|c|c|}
\hline $\mathbf{N}^{\circ}$ & Nome da Igreja & Sigla \\
\hline 1 & Igreja Batista Nova Alvorada & IBNA \\
\hline 2 & Primeira Igreja Batista de Feira de Santana & PIB \\
\hline
\end{tabular}

Para validar a metodologia deste trabalho, os procedimentos identificados neste estudo possuem proximidade com as pesquisas de França (2007); Stephano e Buesa (2013); Freitas (2014); Rodrigues (2014) e Faria e Rego (2014). E para consolidação dos resultados foram emitidos os devidos cálculos, gráficos e tabelas utilizando a ferramenta MC Excel 2010.

Portanto, com o objetivo de verificar o uso da contabilidade como ferramenta promotora de transparência, o questionário foi dividido em blocos, sendo que o primeiro buscou informações acerca do perfil dos gestores: idade, experiência, escolaridade e formação dos pastores a frente das atividades, quantidade de membros da igreja, tempo da igreja, receita média anual etc.

Enquanto o segundo tópico de abordagem fez jus a questionar o sobre o uso da contabilidade e uso de controles internos como: realização de escrituração: uso de contabilidade interno ou externa; acompanhamento de patrimônio; se possui funcionários ou colaboradores realizando atividades de tesouraria, registros e relatórios de entradas e saídas (fluxo de caixa) etc.

O último bloco foi exclusivo para verificar o uso da contabilidade como objeto de transparência, neste sentido, as perguntas envolveram aspectos relacionados aos meios de comunicações utilizados pelos pastores para transitar as informações aos membros; e os tipos de relatórios utilizados, sobre a existência de um órgão ou conselho interno para realização de auditoria e controle de contas (Compliance).

\section{RESULTADOS E DISCUSSÕES}

Para corresponder ao objetivo desta pesquisa em verificar o uso da contabilidade como objeto de transparência pelas Igrejas Batistas de Feira de Santana foram aplicados questionários a duas Igrejas Batistas locais, objetivando analisar o perfil dessas instituições e de seus líderes, o uso da contabilidade e da transparência. Os resultados encontram-se dispostos a seguir.

\subsection{Perfil dos respondentes}

A tabela 2 abaixo apresenta as informações acerca do perfil dos responsáveis das duas igrejas batistas da amostra desta pesquisa. Ressalta-se que o respondente da IBNA foi o presidente do conselho deliberativo da entidade, enquanto o participante da PIB foi o próprio pastor. 
Tabela 2. Perfil dos respondentes

\begin{tabular}{|c|c|c|}
\hline Sexo & IBNA & PIB \\
\hline Masculino & $x$ & $x$ \\
\hline \multicolumn{3}{|l|}{ Feminino } \\
\hline Idade (em anos) & IBNA & PIB \\
\hline \multicolumn{3}{|l|}{$18-23$} \\
\hline \multicolumn{3}{|l|}{$24-29$} \\
\hline \multicolumn{3}{|l|}{$30-35$} \\
\hline \multicolumn{3}{|l|}{$36-41$} \\
\hline \multicolumn{3}{|l|}{$42-47$} \\
\hline $48-53$ & & $\mathrm{x}$ \\
\hline $54-59$ & $x$ & \\
\hline \multicolumn{3}{|l|}{$60-65$} \\
\hline \multicolumn{3}{|l|}{$66-71$} \\
\hline \multicolumn{3}{|l|}{$72-79$} \\
\hline \multicolumn{3}{|l|}{ Mais de 80} \\
\hline $\begin{array}{l}\text { Tempo de Experiência à frente da } \\
\text { Igreja (em anos): }\end{array}$ & IBNA & PIB \\
\hline $1-5$ & $\mathrm{x}$ & \\
\hline \multicolumn{3}{|l|}{$6-10$} \\
\hline \multicolumn{3}{|l|}{$11-15$} \\
\hline \multicolumn{3}{|l|}{$16-20$} \\
\hline \multicolumn{3}{|l|}{$21-25$} \\
\hline $26-30$ & & $x$ \\
\hline \multicolumn{3}{|l|}{31 ou mais } \\
\hline Possui outra atividade profissional? & IBNA & PIB \\
\hline Sim & $x$ & \\
\hline Não & & $x$ \\
\hline Recebe proventos da Igreja? & IBNA & PIB \\
\hline Sim & & $x$ \\
\hline Não & $x$ & \\
\hline $\begin{array}{l}\text { É registrado como funcionário } \\
\text { efetivo da Instituição? }\end{array}$ & IBNA & PIB \\
\hline \multicolumn{3}{|l|}{ Sim } \\
\hline Não & $x$ & $x$ \\
\hline Escolaridade: & IBNA & PIB \\
\hline \multicolumn{3}{|l|}{ Ensino Fundamental } \\
\hline \multicolumn{3}{|l|}{ Ensino Médio } \\
\hline \multicolumn{3}{|l|}{ Ensino Superior Incompleto } \\
\hline Ensino Superior Completo & $x$ & $x$ \\
\hline Pós/MBA & & $x$ \\
\hline Mestrado & & $x$ \\
\hline Doutorado & & \\
\hline
\end{tabular}

\begin{tabular}{c|c|c}
\hline Formação (Graduação): & IBNA & PIB \\
\hline Psicologia & & \\
\hline Pedagogia & & \\
\hline Engenharia & & \\
\hline História & & \\
\hline Administração & $\mathrm{x}$ & $\mathrm{x}$ \\
\hline Filosofia & & \\
\hline Teologia & & $\mathrm{x}$ \\
\hline
\end{tabular}

Nota-se algumas semelhanças entre os respresentantes das igrejas da amostra. Por exemplo, quanto as semelhanças, em relação ao sexo, ambos os responsáveis pelas igrejas são homens, e quanto a idade, também se assemelham, enquanto o representante da IBNA tem idade entre 48-53, o responsável pela PIB possui idade entre 54-59 anos.

Observa-se ainda que semelhantemente os dois respondentes não possui vinculo contratual nas igrejas, ambos com nível superior completo e graduados em administração. Contudo, o respondente da Primeira Igreja Batista informou que possui título de especialista e mestrado, além de uma segunda graduação em teologia.

Mas o destaque nas respostas é nas diferenças entre o perfil dos respondentes. Observado o tempo de experiência na atividade desempenhada, o representante da Igreja Batista Nova Alvorada possui pouco tempo no cargo de presidente do conselho deliberativo, na faixa de 1 a 5 anos, enquanto o pastor da PIB tem mais de 26 e menos de 30 anos nesta função.

Com relação ao recebimento de proventos ou ajuda de custo, o presidente do conselho da IBNA não recebe nenhum valor, mas possui outra atividade profissional. Em contraparte, o pastor da Primeira Igreja Batista recebe proventos mas dedica-se exclusivamente a atividade pastoral.

Esta ideia de dedicação exclusiva ao ministério é tambem o pensamento de White (2018) que infere que é necessário que os pastores, a fim de cumprir as sagradas escrituras, que os pastores sejam homens de devoção vital. 


\subsection{Perfil das Igrejas}

Em relação ao perfil das igrejas, a tabela 3, a seguir apresenta as informações de tempo de fundação, quantidade de membros, receita anual e também a quantidade de trabalhadores registrados no setor de finanças, captadas com ambos os representantes das instituições.

Tabela 3. Perfil das igrejas

\begin{tabular}{|c|c|c|}
\hline $\begin{array}{l}\text { Tempo de fundação da Igreja } \\
\text { (em anos): }\end{array}$ & IBNA & PIB \\
\hline \multicolumn{3}{|l|}{$1-5$} \\
\hline \multicolumn{3}{|l|}{$6-10$} \\
\hline \multicolumn{3}{|l|}{$11-15$} \\
\hline $16-20$ & $x$ & \\
\hline \multicolumn{3}{|l|}{$21-25$} \\
\hline \multicolumn{3}{|l|}{$26-30$} \\
\hline \multicolumn{3}{|l|}{$35-40$} \\
\hline $41-45$ & & $x$ \\
\hline \multicolumn{3}{|l|}{$46-50$} \\
\hline 51 ou mais & & \\
\hline
\end{tabular}

\begin{tabular}{ccc}
\hline $\begin{array}{c}\text { Quantidade de Membros e } \\
\text { Congregados (em pessoas): }\end{array}$ & IBNA & PIB \\
\hline Até 200 & $\mathrm{x}$ & \\
\hline $201-300$ & & \\
\hline $301-400$ & & \\
\hline Mais de 400 & $\mathrm{x}$ \\
\hline
\end{tabular}

\section{Receita anual aproximada em 2018 (em reais): \\ IBNA PIB}

\begin{tabular}{cc}
\hline Até $120.000,00$ & $x$ \\
\hline $120.000,01-200.000,00$ & \\
\hline $200.000,01-300.000,00$ & \\
\hline $300.000,01-400.000,00$ & \\
\hline Mais de $400.000,01$ \\
$x$ \\
\hline $\begin{array}{c}\text { Possui colaboradores trabalhando } \\
\text { no setor de finanças e tesouraria? }\end{array}$ \\
\hline Sim \\
\hline Não \\
\hline
\end{tabular}

\begin{tabular}{ccc}
$\begin{array}{c}\text { Quantidade de colaboradores } \\
\text { registrados: }\end{array}$ & IBNA & PIB \\
\hline Nenhum & & \\
\hline Até 3 & $\mathrm{X}$ & \\
\hline Entre 4-6 & & $\mathrm{x}$ \\
\hline Mais de 7 & & \\
\hline
\end{tabular}

A tabela 3 apresenta que a IBNA possui tempo de fundação inferior a PIB, 16-20 anos e mais de 41 anos, respectivamente. Além disso possui também menos membros e congregados, com no máximo 200 contra mais de 400 da outra instituição. Destes membros, a IBNA tem 3 deles como colaboradores registrados e a PIB tem entre 4 e 6 .

As receitas anuais também são bem distantes: enquanto a Batista Nova Alvorada tem receita de, no máximo 120.000,00; a Primeira Igreja, tem, geralmente, mais de 400.000,00 de receita anual. Esta última tem, ao menos, um funcionário alocado com responsabilidade de registrar as transações financeiras da entidade, enquanto a IBNA não possui ninguém trabalhando nestes setores de tesouraria e finanças.

Acerca desse registro, e de manter um colaborador ativo neste setor, Hoji (2001, p. 185) entende que a tesouraria é um setor de suma importância nas igrejas, pois é através dela que se mantém o controle primário das transações de entradas e saídas dos recursos financeiros, assegurando os recursos e instrumentos financeiros necessários para a manutenção e viabilização dos negócios.

Em relação a receita, assim como as pesquisas de França (2007) e Faria e Rego (2014) foi questionado acerca da origem dos recursos captados pelas igrejas. Os resultados podem ser observados na tabela 4 . 
Tabela 4. Classifiação da importância das receitas recebidas

\begin{tabular}{|c|c|c|c|c|c|c|}
\hline \multirow[b]{2}{*}{ Tipo de Receita } & \multicolumn{3}{|c|}{$\begin{array}{c}\text { Igreja Batista Nova } \\
\text { Alvorada }\end{array}$} & \multicolumn{3}{|c|}{ Primeira Igreja Batista } \\
\hline & $\begin{array}{l}\text { Não se } \\
\text { aplica }\end{array}$ & $\begin{array}{l}\text { Princi- } \\
\text { pal }\end{array}$ & $\begin{array}{l}\text { Segun- } \\
\quad \text { da }\end{array}$ & $\begin{array}{c}\text { - Não se } \\
\text { aplica }\end{array}$ & $\begin{array}{l}\text { Princi- } \\
\text { pal }\end{array}$ & $\begin{array}{l}\text { Segun- } \\
\text { da }\end{array}$ \\
\hline Dízimos & & $x$ & & & $x$ & \\
\hline Ofertas & & & $x$ & & & $x$ \\
\hline $\begin{array}{l}\text { Rendas } \\
\text { patrimoniais }\end{array}$ & $\mathrm{x}$ & & & $\mathrm{x}$ & & \\
\hline $\begin{array}{l}\text { Doações de } \\
\text { empresas ou } \\
\text { governo }\end{array}$ & $\mathrm{x}$ & & & $\mathrm{x}$ & & \\
\hline $\begin{array}{c}\text { Outras rendas } \\
\text { permitidas por } \\
\text { Lei }\end{array}$ & $x$ & & & $\mathrm{x}$ & & \\
\hline
\end{tabular}

A tabela 4 infere que ambas as igrejas recebem os dízimos como receita principal e as ofertas como secundárias e ambas não possuem rendas patrimoniais, doações advindas de empresas ou do governo ou ainda rendas patrimoniais.

Segundo Faria e Rego (2014) os dízimos se referem à parte dos rendimentos dos fiéis que é destinada ao auxílio da igreja. Na pesquisa dos autores a receita mais abundante é justamente esses dízimos. Este fato se repete nas pesquisas dos autores França (2007) e Freitas (2014). Portanto, considera-se que as receitas com dízimos são circunstanciais na continuidade das atividades nas Igrejas Batistas, justamente por comporem grande parte das receitas, estimadas em mais de $85 \%$, segundo os entrevistados.

\subsection{Utilização da Contabilidade}

A tabela 5 apresenta as informações adquiridas dos questionamentos acerca do uso da ciência contábil nas igrejas participantes da pesquisa.
Tabela 5. Utilização da contabilidade

\begin{tabular}{|c|c|c|}
\hline $\begin{array}{c}\text { Possui registros de entradas e } \\
\text { saídas de proventos (fluxo de } \\
\text { caixa)? }\end{array}$ & IBNA & PIB \\
\hline Sim & $x$ & $\mathrm{x}$ \\
\hline \multicolumn{3}{|l|}{ Não } \\
\hline $\begin{array}{l}\text { Possui contabilidade interna e/ou } \\
\text { externa (escritório contratado)? }\end{array}$ & IBNA & PIB \\
\hline \multicolumn{3}{|l|}{ Sim, apenas interna } \\
\hline Sim, apenas externa & $x$ & \\
\hline Sim, ambas & & $x$ \\
\hline \multicolumn{3}{|l|}{ Não, nenhuma } \\
\hline $\begin{array}{l}\text { Como são feitos os registros } \\
\text { financeiros e escrituração contábil? }\end{array}$ & IBNA & PIB \\
\hline \multicolumn{3}{|l|}{ A contabilidade externa faz tudo } \\
\hline \multicolumn{3}{|l|}{ Utilizamos anotações e livros físicos } \\
\hline Utilizamos sistemas de informação & & $x$ \\
\hline Utilizamos planilhas eletrônicas & $x$ & $x$ \\
\hline \multicolumn{3}{|l|}{ Não realizamos controle } \\
\hline Não sei responder & & \\
\hline
\end{tabular}

Acerca do registro do fluxo de caixa, ambas as igrejas realizam o procedimento, inclusive com utilização de planilhas eletrônicas, que possuem um custo baixo. A PIB também possui sistema de informação específico e inclusive setor de contabilidade funcionando internamente, diferente da IBNA que faz sua contabilidade com escritório especializado.

Ressalta-se que o fluxo de caixa, conforme Gomes (2010) é uma ferramenta imprescindível para analisar a situação financeira de qualquer empresa, em geral, bem como verificar o parâmetro atual e perspectiva futura de sobra ou falta de recursos financeiros, administrar as finanças e o próprio ciclo financeiro para o melhor aproveitamento do próprio, assim como a projeção dos saldos dos eventos a pagar e das entradas de recursos. 
Contudo, independente de externa ou interna, os relatórios contábeis são circustanciais para a tomada de decisões. Portanto, foi questionado qual das demonstrações contábeis citadas na tabela 6 são utilizadas pela administação eclesiástica das entidades.

Tabela 6. Demonstrativos contábeis utilizados

\begin{tabular}{c|c|c|c|c}
\hline \multirow{2}{*}{ Demonstrativos Contábeis } & \multicolumn{2}{|c|}{ IBNA } & \multicolumn{2}{c}{ PIB } \\
\cline { 2 - 5 } & Sim & Não & Sim & Não \\
\hline Balanço Patrimonial & & $\mathrm{x}$ & $\mathrm{x}$ & \\
\hline $\begin{array}{c}\text { Demonstração do Superávit/Déficit } \\
\text { do Período - DSDP }\end{array}$ & & $\mathrm{x}$ & $\mathrm{x}$ & \\
\hline $\begin{array}{c}\text { Demonstração das Mutações do } \\
\text { Patrimônio Líquido Social }\end{array}$ & & $\mathrm{x}$ & $\mathrm{x}$ & \\
\hline Balanço Social & & $\mathrm{x}$ & & $\mathrm{x}$ \\
\hline Demonstração do Fluxo de Caixa & $\mathrm{x}$ & & $\mathrm{x}$ & \\
\hline $\begin{array}{c}\text { Demonstrativo de Entradas e } \\
\text { Saídas (receitas e despesas) }\end{array}$ & $\mathrm{x}$ & & $\mathrm{x}$ & \\
\hline $\begin{array}{c}\text { Demonstrativos dos Saldos (caixa } \\
\text { e bancos) }\end{array}$ & $\mathrm{x}$ & & $\mathrm{x}$ & \\
\hline Notas Explicativas & & $\mathrm{x}$ & $\mathrm{x}$ & \\
\hline
\end{tabular}

As principais DC's utilizadas na IBNA são: demonstração de fluxo de caixa, demonstração de entradas e saídas de recursos (específico a entidades do terceiro setor) e as demonstração de saldos de disponíveis (caixa e bancos). Esses itens também são utilizados na PIB.

Contudo, a primeira Igreja Batista faz uso de outros relatórios gerados pela contabilidade, tais como: balanço patrimonial, Demonstração do Superávit/Déficit do Período - DSDP, Notas Explicativas e da Demonstração das Mutações do Patrimônio Líquido Social.

Nenhuma das igrejas utiliza o Balanço Social, contudo, Trevisan (2002) retrata que essa demonstração é muito importante por aproximar a organização da comunidade em que está instalada e com a qual compartilha o meio ambiente e as riquezas necessárias para sua operação. Portanto essa demonstração também auxilia no processo de transparência.

\subsection{Transparência Contábil}

A tabela 7 a seguir possui o objetivo de demonstrar a importância da transparência nas igre- jas e a relação que essa accountability têm com os instrumentos contábeis.

Tabela 7. Transparência e contabilidade

\section{Os resultados financeiros são IBNA PIB apresentados à igreja?}

Sim, a todos os membros registrados

Sim, nas reuniões abertas

Apenas a cúpula administrativa e/ou fiscal

Apenas para o presidente

Não são apresentados

A prestação de contas das finanças

é importante para a igreja obter

recursos que mantenham as suas

IBNA PIB atividades?

\begin{tabular}{ccc}
\hline Sim, concordo totalmente & $x$ & $x$ \\
\hline Não, discordo totalmente & \\
\hline Sim, concordo parcialmente & \\
\hline Não, discordo parcialmente & \\
\hline
\end{tabular}

Se a igreja atuasse sem

transparência haveria uma má

gestão de recursos, muitas pessoas deixariam de contribuir?

Sim, concordo totalmente $\quad x \quad x$

Não, discordo totalmente

Sim, concordo parcialmente

Não, discordo parcialmente

Existe algum fator que necessita

evoluir na transparência financeira IBNA PIB da igreja?

Sim, Qual?

Não, nenhum.

$x$

$\mathrm{X}$

Segundo ambos os representantes das igrejas, os resultados financeiros são apresentados durante as reuniões e essa prestação de contas é circustancial na continuidade da captção dos recursos por parte dos fiéis, fato que demonstra que sem essa accountability, os dízimos e as ofertas iriam reduzir, comprometendo a gestão das igrejas. Ao mesmo tempo que concordam que, no momento, nenhum fator relacionado a transparência é tópico de melhora. 
Quando questionado, no entanto, aos fiés, acerca de possíveis pontos de melhoria, Faria e Rego (2014) obtiveram os resultados que $32 \%$ da amostra em Igrejas Católicas declararam que há fatores que precisam melhorar na prestação de contas, inclusive com citação de sugestões. Contudo, essa pesquisa não objetivou o questionamento aos congregados e membros para realizar possíveis comparações.

\subsection{Análise Geral dos Resultados}

Com o objetivo de verificar o uso da contabilidade como objeto de transparência pelas Igrejas Batistas de Feira de Santana, as principais contribuições desta pesquisa demonstram que o perfil dos respondentes possui particulariedades entre as entidades religiosas.

Enquanto o responsável pelo questionário da IBNA possui pouco tempo de experiência no cargo, com idade entre 48-53, o responsável pela PIB possui idade entre 54-59 anos. Ambos possuem nível superior, com graduação em administração, mas o pastor responsável pela Primeira Igreja Batista tem título de mestre e graduação também em teologia.

As igrejas também possuem uma classificação diferente, a Nova Alvorada tem entre 16 e 20 anos de atuação enquanto a Primeira Batista tem mais de 41 anos de existência. Os rendimentos anuais dessas entidades também são diferentes, pois a IBNA tem faturamento de até $120.000,00$ reais, e a PIB tem, geralmente mais de $400.000,00$ reais de receitas.

Contudo, ambas tem receita principal advinda, primeiramente de dízimos e em segundo: ofertas. Já em relação a quantidade de funcionários registrados, a PIB tem entre 3 a 6; enquanto a IBNA tem menos de 3 colaboradores com registro de carteira de trabalho.

Se tratando da utilização da ciência contábil por parte das entidades religiosas, ambas as igrejas realizam o fluxo de caixa, através de planilhas eletrônicas. Além disso, a Primeira Igreja Batista da cidade. Enquanto a PIN possui contabilidade interna e externa, a IBNA utiliza apenas esta última citada.
Nota-se também que na Primeira Igreja Batista utiliza todos os relatórios, exceto o Balanço Social, enquanto a Nova Alvaorada, utiliza principalmente fluxo de caixa, relatório de entradas e saídas (para receitas e despesas) e o relatório de saldos bancários e de caixa.

Ademais, ambas as igrejas apresentam seus resultados financeiros durante as reuniões visto que entendem que essa prestação de contas é circustancial na continuidade da captção dos recursos por parte dos fiéis, ainda que não necessitem de melhora, entendem que sem essa accountability não existiria ou diminuiria as receitas com dízimos e ofertas.

\section{CONSIDERAÇÕES FINAIS}

O objetivo desta pesquisa consiste em verificar o uso da contabilidade como objeto de transparência pelas Igrejas Batistas de Feira de Santana. Para tanto, foi utilizado metodologia qualitativa e técnica de estudo de caso, com questionário aplicado a duas instituições religiosas pertencentes a Convenção Batista da Bahia e Convenção Batista Brasileira.

Os resultados demonstram que o perfil dos respondentes é de homens experientes, com formação superior, com idade acima de 43 anos, mas abaixo de 59 anos. Estes respondentes são líderes dessas instituições eclesiásticas e possuem, ambos, formação em administração.

As igrejas possuem funcionários registrados $\mathrm{e}$ faz uso da contabilidade para fins fiscais, e, inclusive uma delas utiliza contabilidade também com a finalidade gerencial. As organizações estudadas também se propõem a utilizar os relatórios que a contabilidade oferece, sobretudo o fluxo de caixa.

Considera-se, para os respondentes, que a ciência contábil é uma ferramenta promotora de accountability, e, portanto, os resultados financeiros devem ser apresentados a toda igreja, nas reuniões, com uso dessa ciência como ponte para validar os dados e conferir credibilidade.

Principalmente, porque segundo entendem os quesitonados, responsáveis pelas igrejas, através da transparência é possível manter a captação de recursos, necessários a qualquer organização, na medida em que se propõe a apresentar a origem e destinação dos recursos, objetivo que a contabilidade detém. 
REVISTA

Terceiro Setor

\& Gestão

Portanto, estudos como este, que vinculam a ciência contábil e suas demonstrações podem ser consideradas circustanciais no desenvolvimento do país, pois promovem discussões de caráter social e econômico, inclusive nas empresas sem finalidade lucrativa.

Assim, para futuras pesquisas, sugere-se o investimento de novas teorias, que podem ser desde o aumento da amostra, utilização ou mesclagem de grupos religiosos (religiões) diferenciadas, até o uso de outras empresas, sobretudo do terceito setor, tais como: cooperativas e associações, devido ao aumento da representatividade deste grupo na economia brasileira e contribuição socioeconomica, principalmente por gerar emprego e renda. 

\& Gestão
O USO DA CONTABILIDADE COMO OBJETO DE TRANSPARÊNCIA NAS ENTIDADES RELIGIOSAS: UM ESTUDO DE CASO EM IGREJAS BATISTAS DE FEIRA DE SANTANA Thayná Santos Silva; Mirian Gomes Conceição; Alison Silva Ferreira; Robson Lima Rodrigues

\section{REFERÊNCIAS}

ALBUQUERQUE, A. C. C. Terceiro Setor: história e gestão de organizações. São Paulo: Summus, 2006.

ARAÚJO, O. C. Contabilidade para organizações do Terceiro Setor. São Paulo: Atlas, 2005.

BARROS, A. L. Contabilidade do terceiro setor. In: II Seminário de Iniciação Científica Curso de Ciências Contábeis da FSG, v. 2, n. 1, 2011.

BRASIL. Constituição Federal. Capítulo I: Dos Direitos e Deveres Individuais e Coletivos. Art. $5^{\circ}$, Caput VI. Disponível em: <http://www.planalto.gov.br/ ccivil_03/constituicao/constituicao.htm>. Acesso em: 09 nov. 2018.

BENTO, G. D. Contabilidade e gestão no terceiro setor: um estudo bibliométrico em periódicos nacionais. Universidade Federal de Santa Catarina. Centro Sócio Econômico. Florianópolis, 2010.

CARNEIRO, A. F.; OLIVEIRA, D. L.; TORRES, L. C. Accountability e Prestação de Contas das Organizações do Terceiro Setor: Uma Abordagem à Relevância da Contabilidade. Sociedade, Contabilidade e Gestão, Rio de Janeiro, v. 6, n. 2, jul./dez., 2011.

CERVO, A. L.; BERVIAN, P. A.; SILVA, R. Metodologia científica. 6.ed. São Paulo: Pearson Prentice Hall, 2007.

CONSELHO FEDERAL DE CONTABILIDADE. Interpretação técnica ITG 2002. Entidade sem finalidade de lucros. Disponível em: <http://www. cfc.org.br/sisweb/sre/detalhes_sre.aspx?Codigo=2012/001409> . Acesso em: 10 nov. 2018 .

DRUCKER, P. F. Administração de organizações sem fins lucrativos: princípios e práticas. São Paulo: Learning. 2012.
DUARTE, J.; BARROS, A. (Orgs.). Métodos e técnicas de pesquisa em Comunicação. 2.ed. São Paulo: Atlas, 2006.

FARIA, J. A.; REGO, A. L. S. Transparência nas entidades religiosas: um estudo de caso sobre a aplicação de fatores que contribuem para a transparência financeira na Paróquia Senhor do Bonfim. Revista de Teologia e Ciências da Religião, v. 4, n. 1, p. 267-299, dez., 2014.

FRANÇA, R. D. Sistemas de Controle no Terceiro Setor: um estudo exploratório das Igrejas Batistas da grande João Pessoa. (Dissertação). Programa Multi-institucional e Inter-Regional de Pós-Graduação em Ciências Contábeis, UnB/UFPB/UFPE/UFRN. João Pessoa, 2007.

FREITAS, J. D. A. gestão contábil no terceiro setor: um estudo de caso na Primeira PIBatista de Vitória-ES. (Dissertação). Faculdade Alves Faria. Programa de Mestrado Profissional em Administração, Goiânia, 2014

FONSECA, J. J. S. Metodologia da pesquisa científica. Fortaleza: UEC, 2002.

GERHARDT, T. E.; SILVEIRA D. T. Métodos de Pesquisa. UFRGS. SEAD. 2009.

GIL, A.C. Métodos e técnicas de pesquisa social. 6.ed. São Paulo: Atlas, 2010.

GOMES, C. R. Controle diário e fluxo de caixa. 1.ed. São Paulo: Viena, 2010.

HOJI, M. Práticas de Tesouraria: cálculos financeiros de Tesouraria, operações com derivativos e hedge. São Paulo: Atlas, 2001. 
IBGE. As fundações privadas e associações sem fins lucrativos no Brasil. Estudos \& pesquisas, informação economia 20. Rio de Janeiro, 2012.

IBGE. Censo 2010. Disponível em: <http://www.censo2010.ibge.gov.br/>. Acesso em: 06 nov. 2018.

IUDÍCIBUS, S.; MARTINS, E.; GELBCKE, E. R. Manual de Contabilidade das Sociedades por Ações: aplicáveis demais sociedades. 7.ed. São Paulo: Atlas, 2007.

MARIO, P. C.; ALVES, A. D. F.; CARMO, J. P. S.; SILVA, A. P. B.; JUPETIPE, F. K. N. A Utilização de Instrumentos de Contabilidade Gerencial em Entidades do Terceiro Setor. Sociedade, Contabilidade e Gestão, Rio de Janeiro, v. 8, n. 1, jan./abr., 2013.

MARTINS, O. Contabilidade no Terceiro Setor: conceitos, aspectos, regulamentação e gestão. In: XXII ENECIC, Rio de Janeiro, 2008.

MARTINS, P. L.; NERY, K. P.; BORGES, K.; SOUZA, M. E.; BORGES, R. O. A Contabilidade do Terceiro Setor: o Caso Anália Franco. In: VIII SEGeT - Simpósio de Excelência em Gestão e Tecnologia - 2011.

MEDEIROS, P. M.; GALVÃO, N. M. S.; OLIVEIRA, M. R. G. Relevância da Informação Contábil para Captação de Recursos em Entidades Sem Fins Lucrativos. In: XV Congresso USP de Contabilidade e Controladoria, São Paulo, 2015.

OLAK, P. A.; NASCIMENTO, D. T. Contabilidade para entidades sem fins lucrativos (Terceiro Setor). 3.ed. São Paulo: Atlas, 2010.

PAULSEN, L. Curso de Direito Tributário. 8.ed. São Paulo: Saraiva, 2017.
RODRIGUES, D. M. G. Sistemas de controle no terceiro setor de uma instituição eclesiástica: um estudo de caso na Igreja Evangélica Catedral das Assembleias de Deus - Ministério de Madureira da cidade de Campina Grande - PB. Universidade Estadual da Paraíba. Centro de Ciências Sociais Aplicadas. Campina Grande, 2014.

SÁ, A. L. Fundamentos da contabilidade geral. 3.ed. Juruá Editora: Curitiba, 2008.

SANTOS, P. C.; SILVA, M. E. M. O papel da contabilidade na busca pela sustentabilidade do terceiro setor. Revista Brasileira de Contabilidade, n. 170, mar./abr., 2008, p. 35-46.

SILVA JR., A. F. As obrigações principais e acessórias sob a ótica do terceiro setor numa concepção tributária: Igrejas Evangélicas do Presbitério Vale do Pajeú. (TCC). Universidade Estadual da Paraíba. Centro de Ciências Humanas e Exatas. Monteiro, 2018.

SOUZA, A. F. Análise das demonstrações financeiras na prática. São Paulo: Trevisan, 2015.

STEPHANO, J. Y. K.; BUESA, N. Y. Contabilidade do Terceiro Setor: Enfoque na Contabilidade das Igrejas de Cotia e Itapevi. Revista Eletrônica de Gestão e Negócios, vol. 4, n. 1, 2013.

SZAZI, E. Terceiro setor: regulação no Brasil. São Paulo: Editora Peirópolis, 2006.

TACHIZAWA, T.; POZO, H.; ALVES, J. A. F. Formulação de um plano estratégico em instituições do terceiro setor: o caso de uma ONG de pequeno porte. REUNA, Belo Horizonte, v.17, n.3, jul./set. 2012, p. 53-72.

TREVISAN, F. A. Balanço social como instrumento de marketing. RAE-eletrônica, vol. 1, n. 2, jul./dez. 2002.

WHITE, E. G. Ministério pastoral. Casa Publicadora Brasileira: Rio de Janeiro, 2018. 